\title{
Perception and acceptance of Universal Neonatal Hearing Screening among pregnant women attending a Nigerian Teaching Hospital
}

\author{
Akinola MA', Imaralu JO'2, Ani FIㄹ, Yahaya ${ }^{1}{ }^{1}$, Salami $\mathrm{O}^{1}$, \\ Adefalujo $\mathrm{A}^{3}$
}

1Department of Surgery, ${ }^{2}$ Department of Obstetrics and Gynaecology, ${ }^{3}$ Department of Radio-diagnosis, Benjamin Carson (Snr) School of Medicine and Babcock University Teaching Hospital, Babcock University, Ilishan Remo, Ogun State, Nigeria.

*Correspondence: Dr JO Imaralu, Department of Obstetrics and Gynaecology, Babcock University Teaching Hospital, Ilishan-Remo. Ogun State, Nigeria. E-mail: imaraluj@gmail.com; ORCID - http://orcid.org/0000-0001-8807-3180.

\begin{abstract}
Background: Nigeria reportedly has one of the highest incidences of congenital hearing loss and the Universal Neonatal Hearing Screening (UNHS) offers a potential for early detection and intervention.

Objectives: To determine the awareness and acceptability of newborn hearing screening among the antenatal clinic attendees of a Nigerian Teaching Hospital.

Methods: This study was a cross-sectional survey among the pregnant women attending the antenatal clinic. Data were obtained using semi-structured interviewer-administered questionnaire

Results: A total of 114 women aged 18 and 45 years participated in the survey; 51/114 (44.7\%) were aware of hearing screening with most of them $39 / 51$ (76.5\%) having health workers as their first source of knowledge. A high acceptance rate was obtained among $97 / 114(85.1 \%)$, and this was notably independent $(p=0.399)$ of awareness; $14 / 114(12.2 \%)$ rejected UNHS and the commonest reason for rejection was lack of enough information among 10/14 (71.4\%) on the existence and use of UNHS. Health care workers were the commonest source of information $[39 / 51(76.5 \%)]$. A majority [51/58 (87.9\%)] thought that the best time to initiate treatment is early in life, before speech development, only $4 / 114$ (3.5\%) had relatives who had ever undergone UNHS and all were done abroad.

Conclusions: Less than half of the participants attending ANC were aware of hearing screening and acceptance was high despite this low awareness rate. Parental awareness appeared to depend on contact with healthcare workers. Community education may increase awareness and demand for UNHS.
\end{abstract}

Key Words: Early Intervention, Hearing Impairment, Neonatal Hearing Screening, Pregnant women

\section{Introduction}

Hearing impairment in early life could negatively affect hearing, development and cognitive functions and these, in turn, may limit an individual's capability to achieve life potentials. [1] The diminished ability to get employed and accomplish duties, because of hearing loss may also result from life-altering stigmatization. [1,2] Hearing impaired individuals in developed countries have significantly lower income up to a difference 
of $40-45 \%$ compared to those without hearing loss. The impact is much more in the developing countries. [3]

Hearing loss is the commonest birth defect of any sense organ. ${ }^{[4]}$ The prevalence of hearing loss is 1-3 per 1000 live births in developed countries whereas it is commoner in the developing countries with a prevalence of 4-6 per 1000 live births. ${ }^{[5]}$ Nigeria has one of the highest incidences of sensorineural deafness in infancy. ${ }^{[5,6]}$

Neonatal hearing impairment is mainly sensorineural and the cause could be either genetic or acquired. The genetic causes are responsible for $50 \%$ of newborn hearing losses and $15 \%$ of these occur as part of several syndromes which include Alport, Pendred, Treacher Collin, Usher and Waardenburg syndromes. The other genetic causes of newborn hearing loss are not associated with syndromes; mutations in gene loci that code for plasma membrane proteins like connexin 26 are responsible for this kind of hearing loss. [7] This non-syndromic hereditary deafness is also associated with impairment in potassium and fluid homeostasis in the inner ear. [8] Acquired hearing loss is mainly sensorineural and result from in-utero complications or conditions occurring in the neonatal period. The causes of acquired congenital hearing loss include intrauterine infections such as cytomegalovirus, HIV, toxoplasmosis, herpes simplex, syphilis and rubella. Other contributory conditions include prematurity and low birth weight, hypoxic-ischemic encephalopathy, maternal diabetes mellitus and maternal hypertension. The risk factors for hearing loss of neonatal onset include sepsis, meningitis, oxygen therapy and drugs used in the neonatal intensive care unit (NICU) such as aminoglycosides and frusemide. ${ }^{[7,8]}$ Neonatal hyperbilirubinaemia caused by Glucose-6-Phosphate Dehydrogenase deficiency and Rhesus isoimmunisation can also be complicated by neonatal hearing loss. ${ }^{[9]}$ Hearing loss due to prolonged exposure to noise within the NICU has been an issue of debate in contemporary paediatrics practice. [10] The main sources of high sound pressures which predispose to NICU-onset hearing loss include equipment alarms, such as that produced by mechanical ventilators and sound from conversations between healthcare professionals close to the incubator especially when the incubator door is open. [11] Screening has been shown to drastically reduce the prevalence of preventable disease conditions and ameliorate their effects through early initiation of treatment. [12]

The age at which hearing loss in children is detected by parents and caregivers, in places where UNHS is not available, has been reported to be well over two years, and sometimes as late as six years in some parts of sub-Saharan Africa. [13] The rate of diagnosis of hearing impairment among infants has doubled between 2006 and 2012 with the introduction of the UNHS. This has resulted in increased enrolment in early intervention services for infants diagnosed with hearing impairment from $55.4 \%$ to $61.7 \% .{ }^{[14]}$ Hospitalbased neonatal screening pilot projects done in Nigeria, have confirmed the feasibility of UNHS.[6]

Parental attitude has been shown in studies, to have a significant impact on screening uptake as well as follow-up compliance. ${ }^{[5,15]}$ The health facility where the survey was conducted is poised to initiate the UNHS; an assessment of its acceptability was therefore imperative as part of feasibility checks for the program. Therefore, this study was aimed at determining the awareness of neonatal hearing loss and acceptance of the UNHS among pregnant mothers attending an antenatal clinic.

\section{Methods}

This study was a cross-sectional survey conducted at the Antenatal Clinic of the Babcock University Teaching Hospital 
(BUTH), Ilishan-Remo, located in Ogun state, South-west Nigeria. The study population included pregnant women who were attending the antenatal clinic and within the ages of 18 to 45 years. Women with emergency pregnancy complications and those who failed to consent were excluded.

The minimum sample size was determined using the Leslie Kish formula for estimating a single proportion. ${ }^{[16]}$ The prevalence of hearing loss among low-risk neonates of $6.3 \%$ previously obtained from a study by Botelho $e t$ al was applied to the formula $\mathrm{N}=\mathrm{z}^{2} \mathrm{pq} / \mathrm{d}^{2}$ and a minimum sample size of 100 was obtained after adding $10 \%$ for non-response. [17]

Data were obtained by systematic random sampling, over a six-month period with the aid of semi-structured pre-coded intervieweradministered questionnaire designed by the authors. The number of new antenatal clinic bookings in the previous year (348) was used as the total population, although the total antenatal clinic attendance for the previous year was 2880; this was done to prevent sampling a woman twice. Then, the minimum sample size calculated above as well as the total population was used to create a sampling fraction, i.e every third consecutive pregnant woman. The first unit was arrived at by picking the last digit of a computer-generated random number. The questionnaire contained sections on socio-demographic data, such as age, occupation and educational level using open-ended questions, while the sections on awareness, acceptance and perception of effects of hearing loss and management of hearing loss were structured with 'yes', 'no', and 'don't know' options. The study including the nature of the questions to be asked was explained to the participants by the investigators and trained assistants using the participant information forms, and informed consent was obtained before the interview; the two procedures were carried out in separate consulting rooms.

Each interview lasted 20 minutes on the average. The educational levels were stratified according to the definitions in the National Policy on Education (2004) into 'primary', 'secondary' and tertiary levels.[18]The highest level of education completed was considered as 'educational level' in this study. The occupation was stratified using a modification(according to job description) of the levels of skills by the International Classification of Occupations (ISCO-08).[19] Participants who had no income yielding employment were regarded as 'unemployed', while participants in the ISCO skill level 1 (office assistants, office cleaners, freight handlers, garden labourers and kitchen assistants, which require only primary education) were placed in the category 'unskilled.'The ISCO skill levels 2 and 3 (bus drivers, secretaries, butchers, fashion designers, hairdressers, police officers, shop managers, medical laboratory technicians, radiographers, broadcast and recording technicians, occupations requiring secondary education and higher education of up to 3 years) were categorized as 'skilled' and the ISCO skill level 4 (professionals and managers-medical practitioners, specialized nurses, musicians, secondary school teachers, whose work requires higher education of 3-6 years), were categorized as 'professionals'.

Participants' information was stored in a password-secured personal computer assessable only to the principal investigator. The collected data were analyzed using the Statistical Software Package for Social Sciences (SPSS) version 14.0 (Chicago, Illinois). Frequency tables were made and numerical data expressed as mean (standard deviation). The student $\mathrm{t}$-test was used to compare the mean values of continuous variables while the Chi-Square test was used for the comparison of proportions of categorical variables. The level of statistical significance was set at a pvalue of less than 0.05 .

\section{Ethical considerations}

Ethical clearance was obtained from the Babcock University Health Research Ethics 
Committee (BUHREC), prior to the commencement of the study.

\section{Results}

A total of 120 questionnaires were administered, One hundred and fourteen questionnaires were correctly completed and retrieved, giving a retrieval rate of 114/120 $(95.0 \%)$. The other 6 were not completely filled.

Table I shows that a minority 51/114 (44.7\%) were aware of hearing screening with most of them [39/51 (76.5\%)] reporting health workers as their first source of information. Only 4 $(7.8 \%)$ of the 51 participants who were aware of hearing screening or $4 / 114(3.5 \%)$ of the study population had family members who had ever had hearing screening done. All the reported screening $(100 \%)$ were carried out outside Nigeria.

Table II highlights the determinants of awareness of hearing screening. The mean age of participants who were aware and those not aware of hearing screening programmes were comparable $(p=0.900)$. The educational level attained $(p=0.786)$, occupation $(p=0.156)$, proximity to the study centre $(p=0.356)$ or use of a mobile phone $(\mathrm{p}=0.421)$, were not significantly associated with the participants' level of awareness of UNHS.

Table III shows that the participants' levels of awareness of UNHS did not significantly affect their perception of the possibility of the existence of hearing loss at birth $(p=0.430)$; or the possibility of hearing loss at birth having effects on the quality of life $(p=0.915)$.

Table I: Awareness of newborn hearing screening among ANC attendees

\begin{tabular}{|c|c|c|}
\hline Variables & & Frequency $(\%)$ \\
\hline \multirow[t]{2}{*}{ Awareness $(n=114)$} & Yes & $51(44.7)$ \\
\hline & No & $63(55.3)$ \\
\hline \multirow[t]{4}{*}{ Source of information $(n=51)$} & Friend & $6(11.8)$ \\
\hline & Family & $4(7.8)$ \\
\hline & Health worker & $39(76.5)$ \\
\hline & Social media network & $2(3.9)$ \\
\hline \multirow{2}{*}{$\begin{array}{l}\text { Has family member ever screened } \\
(\mathrm{n}=51)\end{array}$} & Yes & $4(7.8)$ \\
\hline & No & $47(92.2)$ \\
\hline \multirow[t]{2}{*}{ Where was screening done $(n=4)$} & Nigeria & $0(0.0)$ \\
\hline & Abroad & $4(100.0)$ \\
\hline
\end{tabular}

A significantly higher proportion of these respondents who were aware of neonatal hearing screening thought that hearing loss can impair hearing at school $(\mathrm{p}=$ 0.017) and disturb speech development ( $p$ $<0.001)$. However, this was not the case when impaired intelligence was considered $(\mathrm{p}=0.578)$. Table III also shows that a significantly higher proportion of the respondents who were aware of newborn hearing screening believed that hearing loss was treatable $(p<0.001)$, awareness of UNHS had no effect on knowledge of hearing rehabilitation; surgery $(\mathrm{p}=0.516)$, drug treatment $(p=0.809)$, use of hearing aid $(p=0.385)$ or teaching the child to hear $(p=$ $0.263)$.

Most of the respondents [51/58 (87.9\%)] thought that the best time to treat hearing loss is early in life, before the development of speech. This perception was, however, significantly influenced by the awareness of hearing screening $(p=0.006)$.

In Table IV, most participants were unaware of neonatal hearing screening 
but this finding did not significantly affect their perception of the importance of hearing screening in the newborn $(\mathrm{p}=$
0.074 ) and the acceptance of newborn hearing screening $(p=0.399)$.

Table II: Factors associated with awareness of Universal Neonatal Hearing Screening

\begin{tabular}{|c|c|c|c|c|}
\hline \multirow[t]{2}{*}{ Variables } & & \multicolumn{2}{|l|}{ Awareness } & \multirow[t]{2}{*}{ Statistics } \\
\hline & & Yes $(n=51)$ & No $(n=63)$ & \\
\hline \multirow[t]{3}{*}{ Educational level } & Primary (2) & $1(2.0)$ & $1(1.6)$ & $X^{2}=0.680$ \\
\hline & Secondary (53) & $22(43.1)$ & $31(49.2)$ & $\mathrm{df}=2$ \\
\hline & Tertiary (59) & $28(54.9)$ & $31(49.2)$ & $\mathrm{p}=0.786$ \\
\hline \multirow[t]{4}{*}{ Occupation } & Unemployed $(\mathrm{n}=20)$ & 9 (17.6) & $11(17.5)$ & $X^{2}=5.277$ \\
\hline & Unskilled $(n=41)$ & $21(41.2)$ & $20(31.7)$ & $\mathrm{df}=3$ \\
\hline & Skilled $(n=34$ & $10(19.6)$ & $24(38.1)$ & $p=0.156$ \\
\hline & Professional $(\mathrm{n}=19)$ & 11 (21.6) & $8(12.7)$ & \\
\hline \multirow[t]{2}{*}{ Place of residence } & $<5 \mathrm{~km}(\mathrm{n}=66)$ & $31(60.8)$ & $35(55.6)$ & $X^{2}=0.316$ \\
\hline & $>5 \mathrm{~km}(\mathrm{n}=48)$ & $20(39.2)$ & $28(44.4)$ & $p=0.356$ \\
\hline \multirow[t]{2}{*}{ Mobile phone use } & Yes $(\mathrm{n}=111)$ & $49(96.1)$ & $62(98.4)$ & $X^{2}=0.599$ \\
\hline & No $(n=3)$ & $2(3.9)$ & $1(1.6)$ & $p=0.421$ \\
\hline
\end{tabular}

Figures in parentheses are percentages of the total in the respective columns

Table IIIa: Perception of new-born hearing loss, its effects, prevention and treatment-depth of knowledge

\begin{tabular}{|c|c|c|c|}
\hline $\begin{array}{l}\text { Perception of the impact of } \\
\text { Hearing Loss }\end{array}$ & $\begin{array}{l}\text { Aware of } \\
\text { HS } \\
(n=51)\end{array}$ & $\begin{array}{l}\text { Not aware of HS } \\
(n=63)\end{array}$ & Statistics \\
\hline \multicolumn{4}{|l|}{$\begin{array}{l}\text { Can a newborn have hearing } \\
\text { loss }\end{array}$} \\
\hline \multicolumn{4}{|l|}{ Yes $(n=90)$} \\
\hline & $43(84.3)$ & 47 (74.6) & $X^{2}=1.642$ \\
\hline No $(n=20)$ & $7(13.7)$ & $13(20.6)$ & $\mathrm{df}=2$ \\
\hline Do not know $(\mathrm{n}=4)$ & $1(2.0)$ & $3(4.8)$ & $p=0.430$ \\
\hline \multicolumn{4}{|l|}{$\begin{array}{l}\text { Does hearing loss have any } \\
\text { effect on the newborn }\end{array}$} \\
\hline \multicolumn{4}{|l|}{ Yes $(n=69)$} \\
\hline & $30(58.8)$ & 39 (61.9) & $X^{2}=0.244$ \\
\hline No $(n=8)$ & $4(7.9)$ & $4(6.4)$ & $\mathrm{df}=2$ \\
\hline Do not know $(\mathrm{n}=37)$ & $17(33.3)$ & $20(31.7)$ & $p=0.915$ \\
\hline
\end{tabular}

Figures in parentheses are percentages of the total in the respective columns

The commonest reason for acceptance of hearing screening was for early detection of hearing loss among 57/114 (50.0\%), while the most important reason for rejection of newborn hearing screening was the lack of enough information about the existence of such service observed among 10/14 (71.4\%).

\section{Discussion}

The results of this hospital-based survey among antenatal clinic attendees revealed that less than half $(44.7 \%)$ of the participants were aware of universal neonatal hearing screening. This proportion, although higher than the 
$22.5 \%$ obtained from an earlier similar study carried out in Benin City, southern Nigeria, is lower than $89.2 \%$ observed by Gavender et al in a similar study among antenatal clinic attendees in a South African setting where UNHS is readily available. ${ }^{[2,21]}$ Only $3.5 \%$ of the participants had family members whose children ever had a hearing screening at birth and all of these were carried out outside
Nigeria; this finding gives an impression that knowledge of hearing screening depends on the availability of this service. Screening for hearing loss in the newborn is yet to be incorporated into the primary health care programme in Nigeria, even though, hearing loss and deafness are recognised public health problems.[13]

Table IIIb: Perception of new-born hearing loss, its effects, prevention and treatment-depth of knowledge

\begin{tabular}{|c|c|c|c|}
\hline $\begin{array}{l}\text { Knowledge of the effects of } \\
\text { Hearing Loss }\end{array}$ & $\begin{array}{l}\text { Aware of HS } \\
(n=51)\end{array}$ & $\begin{array}{l}\text { Not aware of } \\
\text { HS }(n=63)\end{array}$ & Statistics \\
\hline \multicolumn{4}{|l|}{ Impaired intelligence } \\
\hline Yes $(\mathrm{n}=46)$ & $23(45.1 \%)$ & $23(37.7 \%)$ & $X^{2}=1.265$ \\
\hline No $(n=20)$ & $7 \quad(13.7 \%)$ & $13(21.3 \%)$ & $\mathrm{df}=2$ \\
\hline Do not know $(\mathrm{n}=46)$ & $21(41.2 \%)$ & $25(41.0 \%)$ & $P=0.578$ \\
\hline \multicolumn{4}{|l|}{ Impaired hearing at school } \\
\hline \multicolumn{4}{|l|}{ Yes $(n=76)$} \\
\hline & $41(80.4 \%)$ & $35(55.6 \%)$ & $X^{2}=7.715$ \\
\hline No $(\mathrm{n}=11)$ & $3(5.9 \%)$ & $8(12.7 \%)$ & $\mathrm{df}=2$ \\
\hline Do not know $(\mathrm{n}=27)$ & $7(13.7 \%)$ & $20(31.7 \%)$ & $P=0.017$ \\
\hline \multicolumn{4}{|l|}{ Impaired speech development } \\
\hline \multicolumn{4}{|l|}{ Yes $(n=62)$} \\
\hline & $47(92.2 \%)$ & $15(23.8 \%)$ & $X^{2}=53.549$ \\
\hline No $) n=29$ ) & $1(2.0 \%)$ & $28(44.4 \%)$ & $\mathrm{df}=2$ \\
\hline Do not know $(n=23)$ & $3(5.8 \%)$ & $20(31.7 \%)$ & $\mathrm{P}=<0.001$ \\
\hline \multicolumn{4}{|l|}{$\begin{array}{l}\text { Is the treatment of newborn } \\
\text { hearing loss possible? }\end{array}$} \\
\hline Yes $(\mathrm{n}=58)$ & $3(5.8 \%)$ & $13(20.7 \%)$ & $\mathrm{df}=2$ \\
\hline No $(\mathrm{n}=16)$ & $11(21.6 \%)$ & $29(46.0 \%)$ & $\mathrm{P}<0.001$ \\
\hline Do not know $(n=40)$ & $21(41.2 \%)$ & $25(41.0 \%)$ & $P=0.578$ \\
\hline
\end{tabular}

The developed countries of Europe and America have made neonatal hearing screening mandatory, as a routine care plan for newborn evaluation. [14] The participants' awareness of hearing screening in this study did not depend on educational status, a finding which contrasts a report from an earlier study in the United States (involving male and female parents) where higher levels of parental education were reported among parents who were aware of UNHS. [22] Awareness of neonatal hearing screening in this study had no relationship with the participants' knowledge of the causes or effects of hearing loss. A report from South Africa reported a similar finding, where although $89.2 \%$ of the mothers knew that their newborns could be screened at birth; $60.8 \%$ had the belief that hearing loss in children was mystical while $55.9 \%$ felt that it was a consequence of 'curses' from their enemies. [23] The majority of the participants in this study thought that the best time to commence treatment is in early childhood, before the development of speech. Early identification and treatment of the hearing impaired child give the greatest benefit as regards prevention of speech, learning and psychological effects. $[13,23]$ Studies have also shown that infants who had intervention by the age of six months or earlier, develop normal speech and language.[24] Fulcher, et al. found that the early 
identified children significantly outperformed all severities of hearing loss. [23] the late identified children at all ages and for

Table IIIc: Perception of new-born hearing loss, its effects, prevention and treatment-depth of knowledge

\begin{tabular}{|c|c|c|c|c|}
\hline $\begin{array}{l}\text { Knowledge of } \\
\text { treatment options } \\
\text { for newborn } \\
\text { hearing loss }\end{array}$ & & $\begin{array}{l}\text { Aware of HS } \\
(n=37)\end{array}$ & $\begin{array}{l}\text { Not aware of HS } \\
(n=21)\end{array}$ & Statistics \\
\hline \multirow[t]{3}{*}{ Surgery } & Yes $(n=42)$ & $25(67.6)$ & $17(81.0)$ & $X^{2}=1.646$ \\
\hline & No $(n=9)$ & $6(16.2)$ & $3(14.3)$ & $\mathrm{df}=2$ \\
\hline & Don't Know $(n=7)$ & $6(16.2)$ & $1(4.8)$ & $p=0.516$ \\
\hline \multirow[t]{3}{*}{ Drugs } & Yes $(n=9)$ & $5(13.6)$ & $4(19.0)$ & $X^{2}=7.753$ \\
\hline & No $(n=26)$ & $16(43.2)$ & $10(47.7)$ & $\mathrm{df}=2$ \\
\hline & Don't know $(n=23)$ & $16(43.2)$ & $7(33.3)$ & $p=0.809$ \\
\hline \multirow[t]{3}{*}{ Hearing aid } & Yes $(n=50)$ & $31(83.8)$ & $19(90.5)$ & $X^{2}=2.447$ \\
\hline & No $(n=4)$ & $2(5.4)$ & $2(9.5)$ & $\mathrm{df}=2$ \\
\hline & Don't know $(n=4$ & $4(10.8)$ & $0(0.0)$ & $p=0.385$ \\
\hline \multirow{3}{*}{$\begin{array}{l}\text { Teaching the child } \\
\text { to hear }\end{array}$} & Yes $(n=6)$ & $3(8.1)$ & $3(1.4)$ & $X^{2}=2.742$ \\
\hline & No $(n=40)$ & $24(64.9)$ & $16(76.2)$ & $\mathrm{df}=2$ \\
\hline & Don't know $(n=12)$ & $10(27.0)$ & $2(9.5)$ & $p=0.263$ \\
\hline \multirow[t]{3}{*}{$\begin{array}{l}\text { Timing of } \\
\text { Treatment }\end{array}$} & $\begin{array}{l}\text { Before learning } \\
\text { speech }(n=51)\end{array}$ & $36(97.3)$ & $15(71.4 \%)$ & $X^{2}=7.918$ \\
\hline & $\begin{array}{l}\text { After learning } \\
\text { speech } \quad(n=6)\end{array}$ & $1(2.7)$ & $5(23.8)$ & $\mathrm{df}=2$ \\
\hline & $\begin{array}{l}\text { In adulthood } \\
(\mathrm{n}=1)\end{array}$ & $0(0.0)$ & $1(4.7)$ & $p=0.007$ \\
\hline
\end{tabular}

Figures in parentheses are percentages of the total in the respective columns

Acceptance of UNHS (85.1\%) was higher than the awareness rate $(44.7 \%)$ in the present study. Similar findings were obtained from earlier studies conducted in the Caribbean where $96 \%$ and $50 \%$ showed acceptance and awareness respectively and from Benin City southern Nigeria, where $76 \%$ accepted and were willing to pay out-of-pocket for UNHS although only $22.5 \%$ were aware of the existence of such a service. [20,25]

This observation suggests a high level of trust in the judgement of the health care providers. The observation that a healthcare worker was the source of knowledge in most of the participants in the present study $(76.5 \%)$ who were aware of UNHS, is in support of this assertion. In this study, the commonest reason for acceptance of the newborn hearing screening programme was the fact that it will enable the parents to detect hearing loss early in life. However, the most common reason for rejection of the screening programme was lack of sufficient information. Therefore, information affects parental attitude and attitude in-turn may affect acceptance of UNHS. Reports from earlier studies in Africa have revealed that parental attitude affected the acceptance and uptake of the UNHS. $[5,12,15]$

\section{Conclusion}

Less than half of the participants attending the antenatal clinic have heard of hearing screening but the acceptance of the screening programme was high. Concerted efforts should be made at the community level to improve awareness of hearing screening as parental awareness appeared to depend on contact with healthcare providers. 
Table IV: Participants' knowledge of importance and acceptance of hearing Screening in the newborn

\begin{tabular}{|c|c|c|c|c|}
\hline Variables & & $\begin{array}{l}\text { Aware of HS } \\
(n=51)\end{array}$ & $\begin{array}{l}\text { Not aware } \\
\text { of HS } \\
(n=63)\end{array}$ & Statistics \\
\hline \multirow[t]{3}{*}{$\begin{array}{l}\text { Hearing Screening } \\
\text { is important }\end{array}$} & Yes $(n=99)$ & $48(94.1)$ & $51(81.0)$ & $X^{2}=5.263$ \\
\hline & No $(n=10)$ & $3(5.9)$ & $7 \quad(11.1)$ & $\mathrm{df}=2$ \\
\hline & Declined $(n=5)$ & $\begin{array}{ll}0 & (0.0)\end{array}$ & 5 (7.9) & $\mathrm{P}=0.074$ \\
\hline \multirow[t]{3}{*}{$\begin{array}{l}\text { Reasons for } \\
\text { screening }\end{array}$} & $\begin{array}{l}\text { Preventive purposes } \\
(\mathrm{n}=61)\end{array}$ & $31(60.8)$ & $30(47.6)$ & $X^{2}=2.024$ \\
\hline & $\begin{array}{l}\text { To know newborn baseline } \\
\text { status }(\mathrm{n}=17)\end{array}$ & $6 \quad(11.8)$ & $11(17.5)$ & $\mathrm{df}=2$ \\
\hline & $\begin{array}{l}\text { To create awareness } \\
(\mathrm{n}=36)\end{array}$ & $14(27.4)$ & $22(34.9)$ & $P=0.377$ \\
\hline \multirow[t]{3}{*}{$\begin{array}{l}\text { Acceptance of } \\
\text { hearing screening }\end{array}$} & Yes $(\mathrm{n}=97)$ & 45 (88.2) & $52(82.5)$ & $X^{2}=2.180$ \\
\hline & No $(n=14)$ & $4(7.8)$ & $10(15.9)$ & $\mathrm{df}=2$ \\
\hline & Declined $(n=3)$ & $2(3.9)$ & $1(1.6)$ & $P=0.399$ \\
\hline \multirow[t]{4}{*}{$\begin{array}{l}\text { Reasons for } \\
\text { acceptance }(n=97)\end{array}$} & $\begin{array}{l}\text { Early detection of hearing loss } \\
(n=57)\end{array}$ & $24(53.4)$ & $33(63.5)$ & $X^{2}=2.294$ \\
\hline & $\begin{array}{l}\text { To know baseline status } \\
(\mathrm{n}=33)\end{array}$ & $18(40.0)$ & $15(28.8)$ & $\mathrm{df}=3$ \\
\hline & $\begin{array}{l}\text { To ensure that newborn is fine } \\
(n=6)\end{array}$ & $2(4.4)$ & $4 \quad(7.7)$ & $P=0.415$ \\
\hline & $\begin{array}{l}\text { Should be routine } \\
(n=1)\end{array}$ & $1 \quad(2.2)$ & $\begin{array}{ll}0 & (0.0)\end{array}$ & \\
\hline \multirow{5}{*}{$\begin{array}{l}\text { Reasons for } \\
\text { rejection }(n=14)\end{array}$} & Not necessary & $0(0.0)$ & $1(10.0)$ & $X^{2}=2.463$ \\
\hline & Financial $(n=1)$ & $0(0.0)$ & $1(10.0)$ & $\mathrm{df}=4$ \\
\hline & $\begin{array}{l}\text { Not enough information } \\
(\mathrm{n}=10)\end{array}$ & $4(100.0)$ & $6(60.0)$ & $\mathrm{P}=1.000$ \\
\hline & $\begin{array}{l}\text { All newborns can hear } \\
(\mathrm{n}=1)\end{array}$ & $0(0.0)$ & $1(10.0)$ & \\
\hline & Religious (n=1) & $0(0.0)$ & $1(10.0)$ & \\
\hline
\end{tabular}

Figures in parentheses are percentages of the total in the respective columns

Acknowledgement: The authors express sincere gratitude to the pregnant women who participated in the study and the midwives who helped to ensure seamless data collection.

\section{Authors' Contributions:}

AMA conceptualized the project. AMA, IJO and YO, designed the study, including the protocol and collected data for the study. IJO conducted the data analysis and wrote the initial draft of the manuscript with assistance from AMA. AFI, AMA and AA read and revised the draft manuscript. All authors read the manuscript and approved it for submission.

Conflict of Interest: None declared.

Funding: Self-funded.

Publication History: Submitted 08 April 2018; Revised 16 June 2018; Accepted 23 July 2018.

\section{References}

1. Moeller MP. Early intervention and language development in children who are deaf and hard of hearing. Pediatrics 2000; 106(3):1-9. 
2. Yoshinaga-Itano C. Levels of evidence: Universal newborn hearing screening (UNHS) and early hearing detection and intervention systems (EHDI). J Commun Disord 2004; 37:451-65.

3. Olusanya BO, Ruben RJ, Parving A. Reducing the burden of communication disorders in the developing world: An opportunity for the millennium development project. JAMA 2006; 296: 441-4.

4. Mehl A, Thomson V. Newborn hearing screening: The great omission. Pediatrics 1998; 101(1):1-6.

5. Olusanya BO, Newton VE. Global burden of childhood hearing impairment and disease control priorities for developing countries. Lancet 2007; 369: 1314-7.

6. Olusanya BO, Ruben RJ, Parving A. Reducing the burden of communication disorders in the developing world: An opportunity for the millennium development project. JAMA 2006; 296: 441-4.

7. Bieber FR, Nance WE. Hereditary hearing loss. In: Jackson LG, Schimke RN, eds. Clinical Genetics: A sourcebook for physicians. New York: Wiley; 1978:443-9.

8. Arnos Kathleen. Ethical and social implications of genetic testing for communication disorders. J Commun Disord 2008; 41: 444-57.

9. Bluestone CD. Clinical course, complications and sequelae of acute otitis media. Pediatr Infect Dis J 2000; 19: S37-S46

10. Williams $A L$, van Drongelen $\mathrm{WV}$, Lasky RE. Noise in contemporary neonatal intensive care. J Acoust Soc Am. 2007; 121 (5Pt1): 2681-90.

11. Peixoto PV, Balbino FS, Chimirri V, Pinheiro EM, Kakehashi TY. Internal noise levels in neonatal intensive care unit incubators. Acta Paul Enferm 2011; 24(3): 359-64.

12. Engelman D. "The Status of Neonatal Hearing Screening in Sub-Saharan Africa: A Systematic Review" (2014). CUNY Academic Works. (http://academicworks.cuny.edu/gc_ etds/650) Accessed on 19/10/2017.

13. Ogunkeyede SA, Adebola SO, Salman A, Lasisi AO. Childhood hearing loss; a need for primary health care. Int J Pediatr Otorhinolaryngol 2017; 94: 117-120.

14. Williams TR, Alam S, Gaffney M. Centers for Disease Control and Prevention (CDC). Progress in identifying infants with hearing lossUnited states, 2006-2012. MMWR Morb Mortal Wkly Rep.2015. 10.64 (13):351-6.

15. Swanepoel D, Louw B, Hugo R. A novel service delivery model for infant hearing screening in South Africa. Int J Audiol.2007; 46(6): 321-7.

16. Kish L. Survey Sampling. New York: John Wiley and Sons. Inc. 1965.

17. Botelho FA, Bouzada MC, de Resende LM, SilvaCF, Oliveira EA. Prevalence of hearing impairment in children at risk. Braz J Otorhinolaryngol 2010; 76(6): 739-44.

18. Federal Republic of Nigeria. National Policy on Education. $4^{\text {th }}$ Edition. 2004. NERDC Publishers. 
19. International Standard Classification of Occupations.ISCO-08/International Labour Office. Geneva, ILO, 2012 (www.ilo.org>publication $>$ wcms 172572). Accessed on 15th June 2018.

20. Okhakhu AL, Ntaji MI, Onyeagwara NC, Olusanya BO. Universal Neonatal Hearing Screening: Awareness and Attitude of Mothers Attending the Ante Natal Clinic in a Tertiary Health Facility in Benin City, Nigeria. Ann Biomed Sci 2014; 13(1): 61-7.

21. Govender SM, Khan NB.Knowledge and Cultural Beliefs of Mothers Regarding the Risk Factors of Infant Hearing Loss and Awareness of Audiology Services. J Public Health Afr. 2017; 8(1): 557.

22. Pynnonen MA, Handelsman JA, King EF, Singer DC, Davis MM, Lesperance MM. Parent perception of Newborn Screening: Result of a US National
Survey. JAMA Otolaryngol Head Neck Surg 2016; 142(6): 538-43.

23. Fulcher A, Purcell A, Baker E, Munro N. Listen up: children with earlyidentified hearing loss achieve ageappropriate speech/language outcomes by 3 years-of-age. Int J Pediatr Otorhinolaryngol 2012 76(12): 1785-94.

24. NIH, Early identification of hearing impairment in infants and young children. NIH Consensus statement. 1993; 11(1): 1-24.

25. Kaspar A, Newton O, Kei J, Driscoll C, Swanepoel DW, Goulios H. Parental knowledge and attitudes to childhood hearing loss and hearing services in the Solomon Islands. Int J Pediatr Otorhinolaryngol 2017; 103: 87-92. 